\title{
A INCLUSÃO DA PESSOA COM DEFICIÊNCIA NO MERCADO DE TRABALHO: PERSPECTIVAS SOBRE A EXCLUSÃO PRODUTIVA
}

\author{
LA INCLUSIÓN DE LA PERSONA CON DISCAPACIDAD EN EL MERCADO DE \\ TRABAJO: PERSPECTIVAS SOBRE LA EXCLUSIÓN PRODUCTIVA
}

\section{INCLUSION OF PERSONS WITH DISABILITIES IN THE LABOR MARKET: OUTLOOK ON PRODUCTION EXCLUSION}

\author{
Bianca Gomes da Silva Muylaert MONTEIRO DE CASTRO ${ }^{1}$ \\ Shirlena Campos de Souza AMARAL ${ }^{2}$ \\ Luís Felipe Câmara BORGES ${ }^{3}$
}

RESUMO: O presente trabalho, mediante revisão bibliográfica, busca mostrar como ocorreu a participação social da pessoa com deficiência no mercado de trabalho, mostrando que a participação social está diretamente ligada ao trabalho. As pessoas com deficiência foram, e ainda são, excluídas do mercado de trabalho pela associação que se faz entre deficiência e incapacidade e o trabalho segue esta linha de que a padronização imposta pelo mercado excluiu todos aqueles que não podiam contribuir com o desenvolvimento das forças produtivas. A sociedade atual migra para um estágio no qual as diferenças não mais são vistas como pontos negativos, valorizando os indivíduos por suas singularidades. Para tanto, recorre-se à legislação, que também foi modificada para atender às demandas das minorias, para garantir a igualdade social com base nos princípios constitucionais da isonomia e da dignidade da pessoa humana. Denota-se que o trabalho permite o estímulo ao seu desenvolvimento e constitui um fator decisivo no processo de inclusão social de pessoas com deficiência, sendo indispensável para a construção da individualidade do sujeito como participante ativo da sociedade. Para que ocorra essa construção, faz-se necessária a ação de múltiplos esforços e a participação de todos os segmentos da sociedade, oportunizando alternativas ligadas à inclusão social, de modo a se promover uma verdadeira mudança cultural em relação à diversidade e potencialidades humanas. Dessa forma, resulta-se que os desafios e os enfrentamentos encontrados pelas pessoas com deficiência estão ancorados na história da humanidade, revelando que a sociedade bem-sucedida é aquela que favorece, em todas as áreas, a convivência humana e o respeito à diversidade que a constitui.

PALAVRAS-CHAVE: Pessoa com deficiência. Mercado de trabalho. Inclusão. Exclusão.

\footnotetext{
${ }^{1}$ Universidade Estadual do Norte Fluminense (Uenf), Campos dos Goitacazes - RJ - Brasil. Mestranda em Políticas Sociais. E-mail: biamonteirodecastro@ hotmail.com.

${ }^{2}$ Universidade Estadual do Norte Fluminense (Uenf), Campos dos Goitacazes - RJ - Brasil. Doutora em Ciências Sociais e Jurídicas. Professora Associada da Universidade Estadual do Norte Fluminense Darcy Ribeiro (Uenf). Atua nos Programas de Pós-Graduação em Cognição e Linguagem e Políticas Sociais. Email: shirlenacsa@gmail.com.

${ }^{3}$ Universidade Estadual do Norte Fluminense (Uenf), Campos dos Goitacazes - RJ - Brasil. Aluno especial do Programa de Pós-Graduação em Políticas Sociais. E-mail: felipeborgesadv@gmail.com.
} 
RESUMEN: El presente trabajo, mediante revisión bibliográfica, busca mostrar cómo ocurrió la participación social de la persona con discapacidad en el mercado de trabajo, mostrando que la participación social está directamente ligada al trabajo. Las personas con discapacidad fueron, y todavía son, excluidas del mercado de trabajo por la asociación que se hace entre discapacidad y discapacidad y el trabajo sigue esta línea de que la estandarización impuesta por el mercado excluyó a todos aquellos que no podían contribuir con el desarrollo de las fuerzas Productivas. La sociedad actual migra a una etapa en que las diferencias ya no se ven como puntos negativos, valorando a los individuos por sus singularidades. Para ello, se recurre a la legislación, que también ha sido modificada para atender a las demandas de las minorías, para garantizar la igualdad social con base en los principios constitucionales de la isonomía y de la dignidad de la persona humana. Se dice que el trabajo permite el estímulo a su desarrollo y constituye un factor decisivo en el proceso de inclusión social de personas con discapacidad, siendo indispensable para la construcción de la individualidad del sujeto como participante activo de la sociedad. Para que ocurra esa construcción, se hace necesaria la acción de múltiples esfuerzos y la participación de todos los segmentos de la sociedad, oportunizando alternativas ligadas a la inclusión social para promover un verdadero cambio cultural en relación a la diversidad y potencialidades humanas. De esta forma, resulta que los desafios y los enfrentamientos encontrados por las personas con discapacidad están anclados en la historia de la humanidad, revelando que la sociedad exitosa es aquella que favorece en todas las áreas la convivencia humana y el respeto a la diversidad que La constituye.

PALABRAS CLAVE: Persona con discapacidad. Mercado de trabajo. Inclusión. Exclusión.

ABSTRACT: The present work, through a bibliographical review, seeks to show how the social participation of people with disabilities occurred in the labor market, showing that social participation is directly linked to work. People with disabilities were, and still are, excluded from the labor market by the association between disability and disability, and work follows this line that market-standardized exclusion excluded all those who could not contribute to the development of the forces Productive. Today's society migrates to a stage where differences are no longer seen as negative points, valuing individuals by their singularities. To this end, legislation is used, which has also been modified to meet the demands of minorities, to ensure social equality based on the constitutional principles of isonomy and the dignity of the human person. It is pointed out that work stimulates development and is a decisive factor in the process of social inclusion of people with disabilities, being indispensable for the construction of the individuality of the subject as an active participant in society. In order for such a construction to take place, it is necessary to have multiple efforts and the participation of all segments of society, providing alternatives linked to social inclusion in order to promote a true cultural change in relation to human diversity and potentialities. In this way, it turns out that the challenges and confrontations encountered by people with disabilities are anchored in the history of humanity, revealing that the successful society is one that favors, in all areas, human coexistence and respect for diversity that It constitutes.

KEYWORDS: Disabled person. Job market. Inclusion. Exclusion. 


\section{Breves concepções sobre a pessoa com deficiência}

Pessoas com deficiências sempre fizeram parte dos grupamentos humanos e, como construção sócio-histórica, o conceito de deficiência variou ao longo do tempo. Com o dinamismo social, esta variação não ocorreu linearmente. No entanto, propomos aqui um breve resgate histórico das tendências de pensamento acerca deste tema no decorrer do tempo.

Segundo Pessotti (1984, p. 53-54), durante a antiguidade, as crianças que tinham alguma deficiência eram abandonadas e a imolação era o destino das pessoas com deficiência mental na Grécia Clássica. As pessoas com deficiência menos acentuadas, dependendo da família, poderiam até sobreviver, mas seriam os primeiros a serem eliminados em nome do equilíbrio democrático. Esta atitude era equivalente aos ideais morais da sociedade da época, na qual prevalecia a valorização da perfeição humana.

Na Idade Média, a deficiência era considerada como um fenômeno metafísico e espiritual devido à influência da Igreja; à deficiência era atribuído um caráter ou "divino" ou "demoníaco" e esta concepção, de certa forma, conduzia o modo de tratamento das pessoas com deficiência. Sofriam perseguições, "[...] pois delatores que as entregassem ao tribunal eclesiástico receberiam prêmios em indulgência e outros bens" (SAAD, 2003, p. 40). O confinamento passava a ser a expressão ambivalente de caridade/castigo como atitude benevolente que garantia a sobrevivência.

Sob as ordens de Lutero, diz Schwartzman (1999, p. 4), as pessoas com deficiência e suas mães eram exorcizadas ou até incineradas por serem consideradas frutos da união entre a mulher e o demônio. Já no século XVI, segundo Saad (2003, p. 40-41), “[...] os médicos Paracelso e Cardano demonstraram a preocupação em abordar cientificamente a deficiência, diferenciando-a da abordagem moral ou teológica e, embora não tivessem sistematizado, defendiam a necessidade de tratamento para as pessoas com deficiência".

O advento do cristianismo e a perspectiva humanista de sua doutrina marcaram uma nova visão da sociedade sobre as pessoas com deficiência, uma vez que a proliferação de doenças e da miséria contribuiu decisivamente para a propagação dos ideais de caridade, humildade e amor ao próximo, especialmente entre a população marginalizada e desfavorecida, formada inclusive pelas vítimas de doenças crônicas, de defeitos físicos ou de problemas mentais.

Segundo Bock (1980, p. 69): 
Com relação à ideia de Providencia, afirma-se que só com o advento de uma perspectiva de salvação se pode fugir ao cenário árido dos ciclos; que a perspectiva ecumênica da doutrina cristã era a chave de uma concepção de humanidade como uma entidade que progredia através da história; e que elementos dessa consciência da realidade da vida na Terra, existentes no Cristianismo, estimulavam uma melhoria do cenário humano pela alteração do comportamento dos homens entre si.

Assim, como relata Pessotti (1984, p. 5), o cristianismo tentou considerar todos como "filhos de Deus", inclusive as pessoas com deficiência. Alegava-se que estas também possuíam alma e por isso deveriam ser alvo de caridade. Em consequência, passaram a receber abrigo em igrejas e conventos em troca de alguns serviços, considerando que "qualquer concepção de movimento no sentido do bem tem a necessidade premente de critérios de bondade" (BOCK, 1980, p. 69).

Já na Idade Média, o nascimento de uma pessoa com deficiência era entendido como mau presságio. Seguindo a tendência da época, afloram conceitos discriminatórios e persecutórios, substituindo a caridade pela rejeição àqueles que fugiam de um padrão de normalidade. Sendo assim, “[...] a origem dos estigmas é muito anterior ao Império Romano e os estigmas que foram culturalmente criados subsistem até hoje" (BACILA, 2005).

\section{A terminologia e o senso comum}

Segundo Boaventura de Souza Santos (2003, p. 28), "conhecer significa dividir e classificar para depois poder determinar relações sistemáticas entre o que se separou”. Assim acontece com as classificações que os indivíduos fazem com as coisas ao seu redor e até mesmo com as pessoas, por isso, os indivíduos tendem a se aproximar daqueles que se assemelham a eles e a se afastar daquelas pessoas que são diferentes. Isso se deve ao fato de que:

[...] quanto mais afastado do tipo padrão uma pessoa se apresentar menos humana parecerá aos demais e, em conseqüência, menos direitos lhe serão garantidos. Isso porque, o grupo dominante, que é em geral aquele que personifica o 'tipo ideal', tende a padronizar todo o entorno ao seu redor, de modo que melhor lhe convenha (MACIEL, 2007, p. 163).

Devemos considerar que o denominado "tipo padrão" é um produto social e por isso acompanha a dinâmica social, estando de acordo com o contexto social no qual é 
criado, o que acontece porque "as pessoas não são as mesmas em todos os tempos e todos os lugares" (BOCK, 1980, p. 78), e ainda, "a mudança social é um produto de forças internas da sociedade" (BOCK, 1980, p. 94). Isso corrobora a visão de Santos (2003, p. 36), ao dizer que:

[...] as ciências sociais não podem estabelecer leis universais porque os fenômenos sociais são historicamente condicionados e culturalmente determinados; as ciências sociais não podem produzir versões fiáveis porque os seres humanos modificam o seu comportamento em função do conhecimento que sobre ele se adquire; os fenômenos sociais são de natureza subjectiva e como tal não se deixam captar pela objetividade do comportamento.

A questão da inclusão social e educacional para pessoas com deficiência tem avançado nos últimos tempos, apesar de tratar-se de uma discussão recente, onde a própria terminologia demonstra que não há uma forma permanente no que tange ao assunto. Assim, é preciso compreender que toda vez que atribuímos uma terminologia como representação de algo concreto, nosso imaginário passa a fazer associações que influenciam diretamente na construção da realidade social. Nessa perspectiva, a linguagem torna possível a comunicação e através dela são expressos pontos de vista e opiniões. As narrativas dão sentido à vida social, coordenando o senso comum e construindo cada papel existente na sociedade.

De acordo com Santos (2003, p. 88), senso comum é "o conhecimento vulgar e prático com que no quotidiano orientamos as nossas acções e damos sentido à nossa vida". O senso comum associa deficiência com incapacidade, ignorando que a pessoa com deficiência pode desenvolver potencialidades e habilidades desde que observadas as suas necessidades educativas especiais para que seja possível praticar todas as atividades de uma pessoa considerada normal. Essa equívoca associação é derivada da terminologia usada para representar as pessoas com deficiência.

De acordo com Ribas (2007, p. 12), “deficiência, na língua portuguesa será sempre sinônimo de insuficiência, de falta, de carência e, por extensão de sentido, de perda de vapor, falha, fraqueza, imperfeição”. A palavra representa e estabelece a imagem. D'Amaral (2004) diz que, na palavra deficiente:

O prefixo 'de' tem um sentido inteiramente negativo, como em derrota, 'perda do caminho'; ' perda da rota'; deportado, 'ter sido mandado embora do porto'; desestruturado, 'não estruturado'; deficiente, 'não deficiente'. O prefixo 'de', nesse caso, tem o sentido de 'não', portanto uma negação da própria essência da pessoa como pessoa, porque ela está sendo avaliada por algo que não é pessoal, que 
pertence a uma média e que tem a ver com a produção de efeitos. (...) Se procurarmos olhar e decifrar a palavra deficiência, encontraremos nela uma ambiguidade fundamental: o prefixo que indica negação, privação e a palavra eficiência que indica algo eminentemente positivo (...); o conceito deficiência eivado de preconceitos, traz em si, logo de início, a ideia de diferença e medida, traz a ideia de reconhecimento de diferenças, que inclui na chave da identidade, a diferença, a mensuração das diferenças e a redução do homem e da vida a uma equação de valores, sinais, operações e resultados. (D'AMARAL, 2004, p. 12-24).

Segundo Luiz Alberto David Araújo (2008, p. 911), a questão terminológica revela um avanço na preocupação com as pessoas com deficiência, o que nos mostra que a terminologia correta advém das alterações nos valores e conceitos presentes na sociedade e seu modo de lidar com a questão (SASSAKI, 2003, p. 163).

O termo "pessoas com deficiência" é usado até os dias atuais, ratificado pelos movimentos mundiais de pessoas com deficiência, incluindo os do Brasil, que debatiam o nome pelo qual elas desejam ser chamadas. Mundialmente, parece que a questão foi fechada: até os envolvidos querem ser chamados de "pessoas com deficiência" em todos os idiomas. Esse termo faz parte do texto da Convenção Internacional para Proteção e Promoção dos Direitos e Dignidade das Pessoas com Deficiência, que foi aprovado pela Assembleia Geral da ONU em 2003, e promulgado posteriormente através de lei nacional de todos os Países-Membros, consoante prevê o Decreto Legislativo ${ }^{\circ}{ }^{\circ} 186$, de 9 de julho de 2008; vê-se no artigo 1, in verbis:

Pessoas com deficiência são aquelas que têm impedimentos de longo prazo de natureza física, mental, intelectual ou sensorial, os quais, em interação com diversas barreiras, podem obstruir sua participação plena e efetiva na sociedade em igualdades de condições com as demais pessoas.

Dessa forma, adotou-se a expressão "pessoas com deficiência", buscando-se fomentar o valor agregado às pessoas, visando um empoderamento (SASSAKI, 2005, p. 4). O ponto importante é que o termo afasta um possível viés discriminatório, na medida em que centra o foco na própria pessoa.

\section{Estado, sociedade e direitos da pessoa com deficiência}

Inicialmente, deve-se entender que, a pessoa com deficiência é, antes de tudo, no Estado de direito, um cidadão, e que as "restrições de participação" que as pessoas com deficiência encontram na sociedade resultam das dificuldades e barreiras causadas pelos 
ambientes sociais e físicos. Por isso, faz-se necessário observar que as pessoas com deficiência têm o direito de fazer parte da sociedade inclusiva, sem permanecerem segregadas, cabendo ao Estado e à sociedade identificar nas diferenças todos os direitos que lhes são pertinentes e, a partir daí, encontrar medidas específicas para eliminar, ou ao menos, amenizar as barreiras estruturais e sociais enfrentadas por essas pessoas. Para tanto, a pessoa com deficiência deve ter acesso aos direitos sociais garantidos por lei, exercendo, assim, sua cidadania.

Para Santos (2003, p. 31), "um conhecimento baseado na formulação de leis tem como pressuposto metateórico a ideia de ordem e estabilidade do mundo, a ideia de que o passado se repete no futuro". O passado pode se repetir no futuro, mas o passado também pode trazer reflexos das desigualdades estabelecidas historicamente que geram cada vez mais a necessidade de equiparação.

No Brasil existe um avanço gradual em relação à inclusão da pessoa com deficiência por instrumentos normativos, como a legislação que estabelece obrigatoriedade de cotas concernente à contratação de empregados com deficiência, bem como em reserva de vagas em instituições de ensino. Essas cotas são derivadas de ações afirmativas que objetivam a redução das desigualdades sociais, conforme define Amaral (2006):

As ações afirmativas são políticas - como tais, intencionais que são criadas para provocar o desenvolvimento de formas institucionais diferenciadas visando, como se viu, a favorecer aquelas pessoas e segmentos que, nos padrões até então institucionalizados, não têm iguais oportunidades de se tornarem membros de uma sociedade que se pensa livre e democrática. (2006, p. 49)

Dessa forma, a existência de políticas de ação afirmativa para pessoas com deficiência é justificada pelo fato de que "a pessoa com deficiência esteve sempre numa posição de desvantagem, vulnerabilidade e desigualdade social, pois sofreu sempre um condicionamento no acesso a determinados recursos considerados como essenciais ao bem estar" (PIMENTA e SALVADO, 2010, p. 158).

Nesse sentido, a legislação vigente dispõe sobre o conceito de inclusão e da necessidade da aceitação das diferenças para uma sociedade igualitária. Ou seja,

A construção de uma sociedade inclusiva é um processo de fundamental importância para o desenvolvimento e a manutenção de um Estado democrático. Entende-se por inclusão a garantia, a todos, do acesso contínuo ao espaço comum da vida em sociedade, sociedade essa que deve estar 
orientada por relações de acolhimento à diversidade humana, de aceitação das diferenças individuais, de esforço coletivo na equiparação de oportunidades de desenvolvimento, com qualidade, em todas as dimensões da vida. (BRASIL, 2001b, p.20).

Assim, as ações afirmativas constituem um mecanismo não apenas de inclusão, mas também de contribuição na diminuição dos déficits de cidadania e de desigualdade social, garantindo aos indivíduos o exercício de direitos fundamentais, com base na igualdade, por meio de proteção e garantias estatais, enfatizando que "a mudança é representada como crescimento: é lenta e gradual e marcada por estágios ou fases, e não por acontecimentos. Os acontecimentos são apenas manifestações do processo de crescimento" (BOCK, 1980, p. 78).

A adoção de cotas para pessoas com deficiência pode ser considerada como um grande avanço na conquista dos direitos para as pessoas com deficiência, tendo em vista que “[...] o progresso ou desenvolvimento ou evolução assim retratado envolve uma melhoria da condição humana" (BOCK, 1980, p. 100).

Para Bock (1980, p. 67),

[...] a ideia de progresso [...] encerra uma imagem detalhada e abrangente de mudança. Envolve orientações específicas da história como registro de acontecimentos. Indica uma interpretação definida e singular das diferenças sociais e culturais e designa um uso de diferenças na construção de teorias de mudança social e cultural.

No entanto, podemos dizer que essa mudança ainda não é efetiva, já que existe uma lacuna entre a legislação existente e as práticas que realmente ocorrem, o que demonstra que "o comportamento humano, ao contrário dos fenômenos naturais, não pode ser descrito e muito menos explicado com base nas suas características exteriores e objectiváveis, uma vez que o mesmo acto externo pode corresponder a sentidos de acção muito diferentes" (SANTOS, 2003, p. 38).

De acordo com Santos (2003, p. 52), "a noção de lei tem vindo a ser parcial e sucessivamente substituída pelas noções de sistema, de estrutura, de modelo e, por último, pela noção de progresso". Porém, essa é uma ideia ainda não efetiva, mas ideal, partindo do pressuposto que as pessoas deveriam internalizar as normas legais e sociais para alcançar o almejado progresso, considerando que "o que pretendem dessas ações não é o que resulta delas na prática” (BOCK, 1980, p. 71). 


\section{A pessoa com deficiência e o mercado de trabalho}

A pessoa com deficiência, muitas vezes, é caracterizada como indivíduo possuidor de limitações e que, devido a estas, encontra inúmeras dificuldades em sua inserção no mundo social e no mundo do trabalho.

Tocqueville (1840), citado por Daniel Bell (1977, p. 63), afirmou que "uma multidão de indivíduos iguais ou parecidos trabalham para atender às suas satisfações próprias". Logo, é possível concluir que os indivíduos diferentes, como os que apresentavam deficiências, eram considerados inservíveis para o trabalho, incapazes, e, por consequência, estigmatizados e excluídos.

Como dito anteriormente, o imaginário social associa deficiência com incapacidade, afastando grandes oportunidades para as pessoas com deficiência, que na verdade são apenas diferentes, em uma sociedade marcada pelas diferenças e diversidade. No entanto, essa é uma diferença marcada negativamente, o que acaba por estigmatizar as pessoas com deficiência.

Segundo Bacila (2005, p. 25), “o estigma gera profundo descrédito e pode também ser entendido como defeito, fraqueza ou desvantagem", na medida em que faz com que a sociedade tenha um tratamento diferenciado em relação às pessoas com deficiência, enxergando-as como incapazes e até mesmo inferiores, como se não pudessem realizar quaisquer atividades.

Corroborando o que foi dito por Bacila, Bock (1980, p. 72) diz ainda que:

Também é claro para Aristóteles, pelo mesmo argumento, que o Estado é 'anterior, pela natureza, ao indivíduo', pois um indivíduo não pode ser auto-suficiente exceto no Estado. $\mathrm{O}$ homem que é incapaz de participar da associação do Estado, ou que não precisa disso, 'deve ser um animal inferior ou um deus'.

Com isso, é possível perceber que:

[...] a partir destas condições, inscritas em diferentes períodos da história ocidental, podemos claramente perceber que em todas elas a pessoa com deficiência esteve sempre numa posição de desvantagem, vulnerabilidade e desigualdade social, pois sofreu sempre um condicionamento no acesso a determinados recursos considerados como essenciais ao bem estar (educação, emprego, saúde) (PIMENTA; SALVADO, 2010, p. 158). 
Dessa forma, podemos ver que as pessoas com deficiência formam uma minoria que precisa ter seus direitos garantidos pelo Estado para que possa ocupar seus lugares na sociedade.

Ao citar Marx e Bell (1977, p. 71) diz que ele "prevê a contínua expansão da produção capitalista que absorverá a sociedade toda". Com isso, podemos perceber que as pessoas que não podem ser absorvidas não são sequer lembradas, e isso se deve ao fato de que elas "permanecem fora do processo capitalista".

Bell (1977, p. 91) diz ainda que "Aron organizou o conceito de sociedade industrial em torno do eixo do desenvolvimento econômico", nos fazendo considerar que as pessoas que não podiam participar desse desenvolvimento econômico eram excluídas por não terem “forças de produção”. Isso acontece porque:

As sociedades industriais são sociedades orientadas para a Economia, isto é, organizadas em torno de um princípio de eficiência funcional, (...) Nessa medida, a ideologia perde sua importância e é substituída pela 'economia' sob as aparências de funções de produção, de relações de produção, de capital, de eficiência marginal do capital, de programação linear, etc. (BELL, 1977, p. 92).

Bell (1977, p. 65) refere-se a Ralf Dahrendorf quando este afirma que "pouca coisa se transfere do emprego para outras áreas da vida". No entanto, sabemos que atualmente a sociedade é definida profissionalmente.

Justamente por essa capitalização social, fica evidente que, ao desejarem ter uma participação ativa na sociedade, as pessoas querem ingressar no mercado de trabalho. Isso ocorre porque nos dias atuais acontece a personificação de nossas práticas profissionais, que acabam nos definindo, e definindo os papéis sociais que desempenharemos.

Apesar disso, é preciso observar que, por muito tempo e ainda hoje, numa sociedade capitalista, quem não tem força de trabalho está excluído porque não entra na lógica do mercado no que se refere à produtividade.

Assim, podemos perceber que, atualmente, a busca pelo lugar no mercado de trabalho faz com que as pessoas queiram se capacitar para aprimorar seus conhecimentos. No entanto, ao tentar ingressar nesse mercado de trabalho, as pessoas com deficiência se deparam com as exigências do mundo globalizado, como o "enxugamento dos postos de trabalho, desemprego e aumento do trabalho informal" (FRANÇA, 2008, p. 115). Entretanto, é preciso considerar que: 
O princípio do movimento de vida independente está valorizado quando se assinala a autonomia e independência individuais das pessoas com deficiência, inclusive da liberdade delas fazerem suas próprias escolhas, e participarem ativamente das decisões relativas a programas e políticas públicas, principalmente as que lhes dizem respeito diretamente (RESENDE; VITAL, 2008, p. 24).

Essa mudança que se busca no patamar de direitos da pessoa com deficiência ocorre principalmente como efetivação do princípio constitucional da igualdade e da dignidade da pessoa humana, nos quais se fundam a Constituição Brasileira de 1988, que diz que "todos são iguais perante a lei", contribuindo para o entendimento de que:

Todo indivíduo é definido por sua situação sociológica, e é membro de uma classe específica, ou Stande, que define seus direitos e obrigações. Trata-se de uma sociedade que fundamenta tanto o status social como o político; o termo Stande refere-se ao mesmo tempo à estratificação social e à organização política (BELL, 1977, p. 99).

Assim, no que se refere aos direitos das pessoas com deficiência, vemos a necessidade de que o Estado as represente e institua normas que tenham por objetivo uma reformulação política para que exista uma transformação social, visando o interesse da coletividade e não privilegiando algumas minorias e excluindo outras. Segundo Bell,

Para Hegel, de quem se extraiu esta distinção básica, a sociedade civil constituía uma reunião de interesses especiais, buscando cada qual atingir seus próprios objetivos, enquanto o Estado representava o 'interesse geral', ao governar em benefício de todos. (BELL, 1977, p. 99)

Nesse contexto, fica clara a necessidade do Estado para o desenvolvimento social, tendo em vista que: “[...] o que era decisivo não era apenas a política, mas também a estrutura social. A política é uma arena onde entram em choque as divisões sociais de uma sociedade. A política não tem autonomia; é um reflexo das forças de organização social” (BELL, 1977, p. 101).

Apesar das pessoas com deficiência não formarem uma classe social, porque a deficiência não define ou depende de classes sociais, "[...] a técnica de classificar os indivíduos ou suas famílias em grupos sociais segundo a sua posição social, vagamente definida, na comunidade, dá ampla liberdade aos caprichos do observador" (PARKIN, 1980, p.785). 
Parkin (1980, p. 786), ao analisar as teorias de Warner e Weber sobre classes sociais, grupos de status e estratificação, concluiu que:

[...] a diferença crucial era a de que Weber geralmente considerava os grupos de status como formações sociais que surgiram dentro de amplas categorias de classe; nunca os considerou como equivalentes de classes em si mesmos. Nos estudos de Warner, os grupos sociais de status são construídos num vácuo de classe total, de modo que, em lugar de serem tratados como um aperfeiçoamento da análise de classes, eles acabam sendo um substituto dela.

Nessa perspectiva, entendemos que as pessoas com deficiência estão presentes em todas as classes sociais, mas formam um grupo de status com características de minoria, o que é confirmado pela visão de Weber (PARKIN, 1980, p. 787) de que “[...] as dimensões da estratificação não foram nunca consideradas como agregados de atributos individuais, mas como fenômenos da distribuição de poder”.

Sobre essa "distribuição de poder", podemos associar as formas de dominação e socialização existentes nas sociedades em que, “[...] diz Lichtheim, a legislação do bemestar social e a redistribuição das rendas 'constituem aspectos de um processo de socialização' que circunscrevem a operação de uma economia de mercado" (BELL, 1977, p. 67).

Com vistas a participar dessa distribuição de rendas e poder, as pessoas com deficiência buscam se qualificar e capacitar para tornar possível a sua inserção no mercado de trabalho, principalmente por meio da Lei de Cotas - Lei 8.213/91 -, que vem atuando para garantir a inclusão dessas pessoas no campo profissional, através da reserva de vagas em empresas que possuam mais de cem funcionários, com o desígnio de reduzir a exclusão social das pessoas com deficiência e objetivando reduzir desigualdades e vulnerabilidades sociais.

\section{Considerações finais}

O presente trabalho mostrou que as pessoas com deficiência sempre estiveram à margem da sociedade, por serem consideradas incapazes para o trabalho, que cada vez mais define os papéis sociais. Assim, essa exclusão do mercado de trabalho, gera, por consequência, a exclusão social, em razão do senso comum de que existe ausência de forças produtivas por parte das pessoas com deficiência.

Foi possível perceber que o estigma é um fator que cria obstáculos na equalização das oportunidades de acesso ao mercado de trabalho, já que a deficiência 
não pressupõe o total cerceamento das habilidades para o exercício laborativo, não significando que aquele que possua a necessidade de atendimento especial seja plenamente incapaz de exercer qualquer atividade dentro do mercado de trabalho.

No entanto, o estereótipo gerado socialmente é que toda pessoa com deficiência é incapaz, o que não corresponde à realidade, pois tal visão limita as múltiplas habilidades humanas que independem de um único sentido. Neste viés, vemos a participação do Estado quando este cria institutos jurídicos que visam garantir a participação da pessoa com deficiência no mercado de trabalho e também a sua inclusão social.

Assim, concluímos que a exclusão, imputada às pessoas com deficiência, de algum modo, pode ser diluída quando se existe estímulo inclusivo mediante políticas de ação afirmativas que acabam por corroborarem no encontro das múltiplas potencialidades da pessoa com deficiência com o mercado de trabalho, mas enquanto a legislação avança, o que falta são políticas sociais voltadas à implementação e concretização dos direitos dessas pessoas, uma vez que o Brasil, segundo o IBGE, possui um grande número de pessoas com deficiência em contrapartida a uma das menores taxas de participação dessas pessoas no mercado de trabalho.

AGRADECIMENTOS: FAPERJ/UENF.

\section{REFERÊNCIAS}

AMARAL, Shirlena Campos de Souza. $O$ acesso do negro às instituições de ensino superior e a política de cotas: possibilidades e limites a partir do "caso" UENF. Dissertação (Mestrado em Políticas Sociais). Campos dos Goytacazes: PPGPS/UENF, 2006.

ARAÚJO, Luiz Alberto David. A proteção constitucional das pessoas portadoras de deficiência. 2. ed. Brasília: Coordenadoria Nacional para Integração das Pessoas Portadora de Deficiência, Ministério da Justiça, 1997.

ARAÚJO, Luiz Alberto David. A proteção constitucional das pessoas portadoras de deficiência: algumas dificuldades para efetivação dos direitos. In: SARMENTO, Daniel.; IKAWA, Daniela.; PIOVESAN, Flávia (coords.). Igualdade, diferença e direitos humanos. Rio de Janeiro: Lúmen Júris, 2008, p. 911-923.

BACILA, Carlos Roberto. Estigmas, um estudo sobre os preconceitos. Lumen Juris. Rio de Janeiro, 2005. 
BELL, Daniel. O avento da sociedade pós-industrial: uma tentativa de previsão social. São Paulo: Cultrix, 1977.

BOCK, Keneth. Teorias do progresso, desenvolvimento e evolução. In: BOTTOMORE NISBET, Robert. História da análise sociológica. Rio de Janeiro: Zahar, 1980. p. 65 117.

BRASIL. Lei $\mathbf{n}^{\mathbf{0}} \mathbf{. 1 0 . 0 9 8}$, de 19 de dezembro de 2000.

BRASIL. Constituição da República Federativa do Brasil. Brasília, DF: Senado Federal, 1988.

BRASIL. Decreto Legislativo no 186, de 9 de julho de 2008.

BRASIL. Programa Nacional de Direitos Humanos - PNDH. 11 ${ }^{a}$ Conferência

Nacional dos Direitos Humanos. Texto-base. Brasília: Secretaria Especial dos Direitos Humanos, 2008.

D’AMARAL, Márcio Tavares. Sem Limite: inclusão de portadores de deficiência no mercado de trabalho. $2^{\mathrm{a}}$ ed, IBDD [coord.] - Rio de Janeiro: Editora SENAC-Rio, 2003.

IBGE. Instituto Brasileiro de Geografia e Estatística, 2010.

MAZZOTTA, Marcos José Silveira. Educação especial no Brasil: história e políticas públicas. 5.ed. São Paulo: Cortez, 2005.

PARKIN, Frank. Estratificação social. In: BOTTOMORE NISBET, Robert. História da análise sociológica. Rio de Janeiro: Zahar, 1980. p. 780-822.

PESSOTI, I. Pré-história do condicionamento. Editora da Universidade de São Paulo: São Paulo, 1976.

PIMENTA, Alexandra, Salvado, Ana. Deficiência e desigualdades sociais. Sociedade e Trabalho, 41, p. 155-166.

PINTO, Paula Campos. Deficiência, sociedade e direitos: a visão do sociólogo.

Disponível em: http://www.icjp.pt/sites/default/files/media/723-1116.pdf. Acesso em: 07 ago. 2014.

RIBAS, João. Preconceito contra as pessoas com deficiência: as relações que travamos com o mundo. São Paulo: Cortez, 2007.

SAAD, Suad Nader. Preparando o caminho da inclusão: dissolvendo mitos e preconceitos em relação à pessoa com Síndrome de Down. São Paulo. Vetor. 2003.

SANTOS, Boaventura de Sousa. Um discurso sobre as ciências. São Paulo: Cortez, 2003.

SASSAKI, Romeu Kasumi. Inclusão: construindo uma sociedade para todos. $4^{\text {a }}$ edição. Rio de Janeiro: WVA, 2005. 
SCHWARTZAN, J. S. Síndrome de Down. São Paulo: Markenzie, 1999.

SILVA, Maria Isabel da. Por que a terminologia "pessoas com deficiência"?

Universidade Federal Fluminense. Núcleo de Acessibilidade e Inclusão Sensibiliza -

UFF, 2009.

\section{Como referenciar este artigo}

CASTRO, Bianca Gomes da Silva Muylaert Monteiro.; AMARAL, Shirlena Campos de Souza.; BORGES, Luís Felipe Câmara. A inclusão da pessoa com deficiência no mercado de trabalho: perspectivas sobre a exclusão produtiva. Revista on line de Política e Gestão Educacional, Araraquara, v.21, n.3, p. 1433-1447, set./dez. 2017. ISSN: 1519-9029.

Submetido em: 30/07/2017

Aprovado em: 26/11/2017 